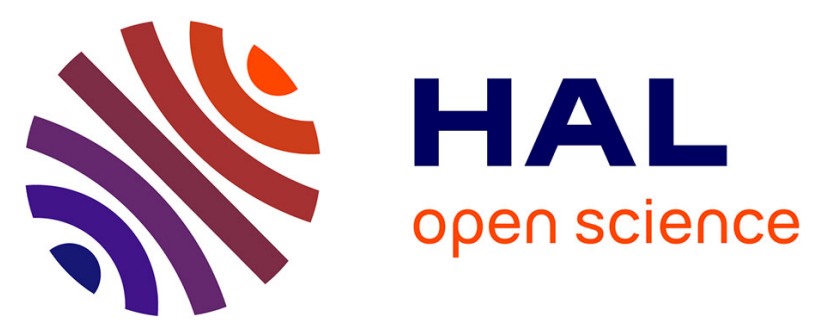

\title{
Electromagnetic Modeling in Near-Field Scanning Microwave Microscopy Highlighting Limitations in Spatial and Electrical Resolutions
}

Petr Polovodov, Charlene Brillard, Olaf C Haenssler, Christophe Boyaval, D. Deresmes, Sophie Eliet, Fei Wang, Nicolas Clement, Didier Theron, Gilles Dambrine, et al.

\section{To cite this version:}

Petr Polovodov, Charlene Brillard, Olaf C Haenssler, Christophe Boyaval, D. Deresmes, et al.. Electromagnetic Modeling in Near-Field Scanning Microwave Microscopy Highlighting Limitations in Spatial and Electrical Resolutions. 2018 IEEE MTT-S International Conference on Numerical Electromagnetic and Multiphysics Modeling and Optimization (NEMO), Aug 2018, Reykjavik, Iceland. pp.1-4, 10.1109/NEMO.2018.8503487 . hal-02155769

\section{HAL Id: hal-02155769 \\ https://hal.science/hal-02155769}

Submitted on 13 Jun 2019

HAL is a multi-disciplinary open access archive for the deposit and dissemination of scientific research documents, whether they are published or not. The documents may come from teaching and research institutions in France or abroad, or from public or private research centers.
L'archive ouverte pluridisciplinaire HAL, est destinée au dépôt et à la diffusion de documents scientifiques de niveau recherche, publiés ou non, émanant des établissements d'enseignement et de recherche français ou étrangers, des laboratoires publics ou privés. 


\title{
Electromagnetic Modeling in Near-Field Scanning Microwave Microscopy
}

\author{
Highlighting Limitations in Spatial and Electrical Resolutions \\ P. Polovodov, C. Brillard, O. C. Haenssler, C. Boyaval, D. Deresmes, S. Eliet, \\ F. Wang, N. Clément, D. Théron, G. Dambrine and K. Haddadi \\ University Lille, CNRS, UMR 8520 - IEMN \\ F-59000 Lille, France \\ kamel.haddadi@univ-lille1.fr
}

\begin{abstract}
Near-field scanning microwave microscopy (NSMM) is a scanning probe microscopy (SPM) technique that measures the local interaction of evanescent microwaves with a sample using a sharp tip probe. The traceability in NSMM is still challenging as the distribution of the electrical fields is affected by several parameters. In this effort, finite element method (FEM) based electromagnetic modeling methods are used to study the effects of the wavelength of operation and the humidity on the spatial and electrical resolutions respectively. From the simulated data, it is demonstrated that the lateral resolution is improved with increasing the frequency of operation. Furthermore, the existence and influence of a water meniscus is highlighted by fine comparison between simulated and measured data. To face these issues, an alternative near-field scanning millimeter-wave microscopy working in a controlled environment is proposed.
\end{abstract}

Keywords- near-field scanning microwave microscopy (NSMM); finite element method (FEM); electromagnetic modeling; vector network analyzer (VNA); scanning electron microscope (SEM).

\section{INTRODUCTION}

The introduction of scanning microwave microscopy (SMM) tools have pioneered many applications, notably including mapping and quantitative measurement of the electrical properties of materials and devices at micro and nano scale [1]-[7]. Basically, the scanning microwave microscope (SMM) consists of an atomic or scanning tunneling microscope combined with a vector network analyzer (VNA) [8]-[9]. The tip scans across the sample, emitting a microwave signal scattered by the material, altering its amplitude or/and phase properties.

Most of the reported NSMM tools operate in the microwave frequency range, i.e. $300 \mathrm{MHz}-30 \mathrm{GHz}$. Consequently, there is a natural mismatch between the probe tip size (tens of $\mathrm{nm}$ ) compared to the wavelength of operation in the order of the $\mathrm{cm}$. When the tip of the probe is held close to the surface of a sample, at a distance separation much smaller than the wavelength of operation, the evanescent electric fields are highly confined in space. In contrast with traditional methods based on propagating waves, microscopy techniques result in high lateral and depth resolutions governed by the tip size.

This work is supported by the French National Research Agency (ANR) under the EquipEx Excelsior (www.excelsior-ncc.eu) and the European Union's Horizon 2020 research and innovation programme under grant agreement No 761036 .
Although it is known that water qualitatively affects the atomic force microscopy and other scanning microscopy tools [10]-[11], the existence of a water meniscus in the vicinity of the probe would have a high collimation effect on the evanescent fields especially due to the relatively high complex permittivity of water in the microwave regime. The water meniscus can be modeled by parasitic complex impedance related to the shape of the water meniscus, dielectric and loss tangent permittivity of water.

There is an urgent need to extend the frequency capabilities of microwave microscopy tools to achieve sub-50nm spatial resolution combined with sub-aF electrical resolution. In this effort, finite element method (FEM) based electromagnetic modeling methods are proposed to study accurately the limiting factors. In Section II-a, a 12Pt400B microwave probe from Rocky Mountain Nanotechnology ${ }^{\circledR}(\mathrm{RMN})$ consisting in an ultra-sharp solid platinum wire tapered down to $50 \mathrm{~nm}$ and attached to a ceramic substrate is considered is designed in the ANSYS ${ }^{\circledR}$ HFSS to simulate the 3D full-wave electromagnetic fields in the vicinity of the probe in the microwave and millimeter-wave regimes. In Section II-b, sub-100 nm capacitors with targeted capacitance values in the order of few aF are characterized by NSMM. Retro-simulated data using FEM COMSOL ${ }^{\circledR}$ multiphysics to model the tip-sample interaction in the presence of water shows exemplary the existence of the water meniscus. In Section III, a near-field scanning millimeter-wave microscope with targeted frequency operation of $110 \mathrm{GHz}$ is described. This latter has been designed to operate inside a scanning electron microscope for environment control and water meniscus elimination.

\section{3D NUMERICAL MODELING AT THE PROBE APEX}

\section{A. Lateral and depth resolutions}

The probe has been simulated using a finite element analysis (Ansys HFSS $®$ ). The distribution of the electrical fields in the vicinity of the probe (in free-space condition) is investigated by means of electromagnetic simulations. Fig. 1 shows the magnitude of the electrical field as a function of the frequency of operation. In the near zone, this graph points out 
clearly that the simulated electrical field yields in better spatial resolution with higher operating frequency.

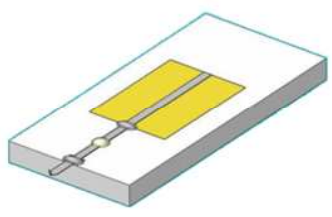

(a)

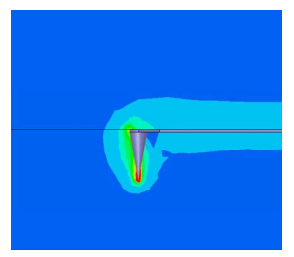

$1 \mathrm{GHz}$

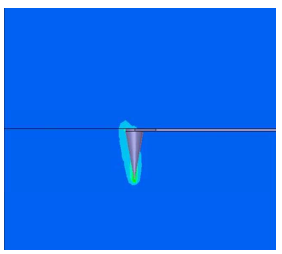

$10 \mathrm{GHz}$

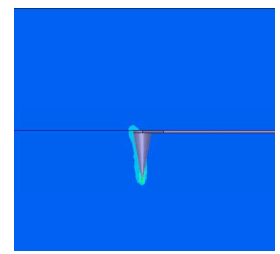

$30 \mathrm{GHz}$ (b)

Fig. 1. (a) RMN ${ }^{\circledR}$ probe configuration. (b) HFSS simulation of the electrical field magnitude as a function of the frequency of operation.

To benefit from the high depth resolution, the material under test must be set at stand-off distance in the order of the apex size. Fig. 2 investigates the electrical fields distribution for various stand-off distances between the probe tip and a planar silicon material at $30 \mathrm{GHz}$. The following figures indicate that both lateral and spatial resolutions are affected for stand-off distances greater than $500 \mathrm{~nm}$. Indeed, the collimation of the electrical fields diminishes.
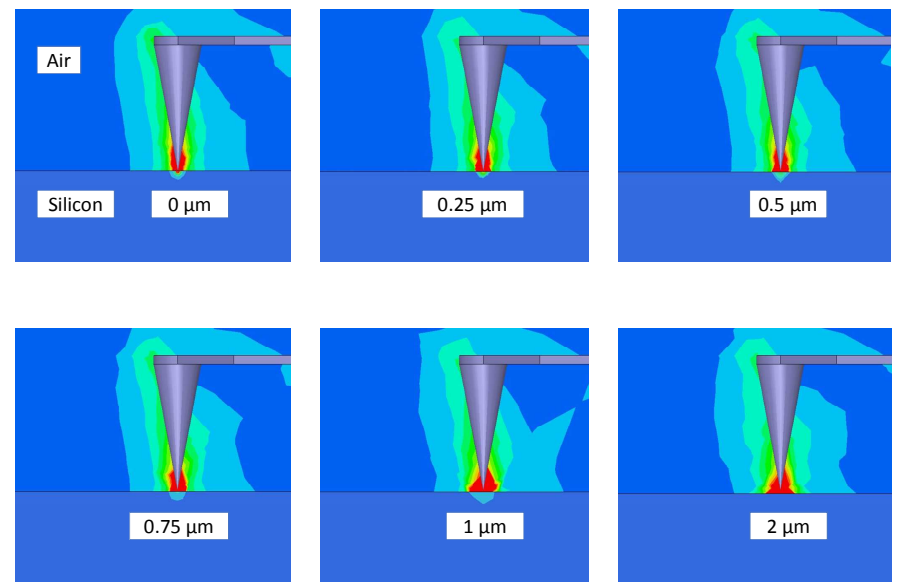

Fig. 2. HFSS simulation of the electrical field magnitude as a function of the stand-off distance $-\mathrm{f}=30 \mathrm{GHz}$.

\section{B. Electrical resolution}

We used an interferometric NSMM for investigating sub-10 nm-diameter nanodot capacitors [12]. The modeling of the nanodot capacitors was done using FEM COMSOL ${ }^{\circledR}$ multiphysics. For nanocapacitance imaging, the NSMM was operated under typical ambient conditions at $7.8 \mathrm{GHz}$. A relative humidity $45 \% \pm 5 \%$ is controlled in the NSMM room. After calibration detailed in [13], the capacitance values are extracted (Fig. 3). Surprisingly, the extracted nanocapacitor values were up to two orders of magnitude larger than those expected from FEM estimations. Such a mismatch is likely related to parasitic capacitances that could arise from the tip cone/substrate capacitance or the water meniscus discussed previously. The first contribution calculated by FEM is rather large ( $\mathrm{fF}$ range) and is in fact taken into account by the calibration process. At the opposite, the water meniscus affects only the nanocapacitors and cannot be taken into account by the calibration procedure. The consideration of the presence of a water meniscus by FEM gives reasonable quantitative agreement with experimental results (Fig. 3).

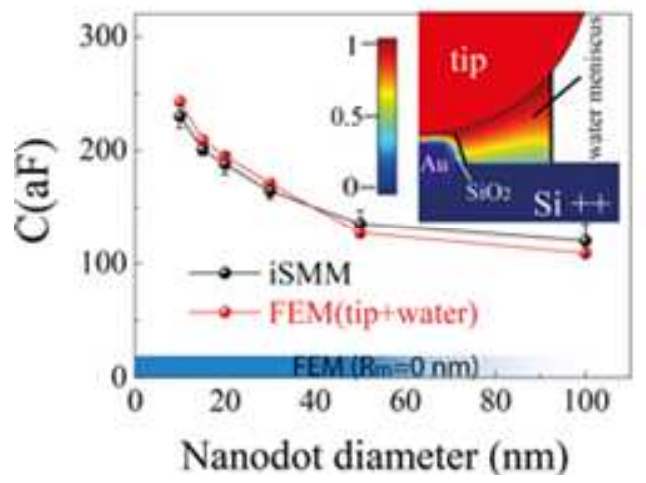

Fig. 3. Capacitance values estimated from NSMM measurements and calibration and from electrostatic simulation for different nanodot dimensions. Inset: cross-section view of the electrical field lines and isopotentials simulated by FEM (COMSOLC) with a water meniscus of radius $65 \mathrm{~nm}$ [13].

\section{DESIGN AND INSTRUMENT DEVELOPMENT}

The block diagram of the proposed system is described in Fig. 4. Operating an NSMM inside a SEM demands considering design conditions different to those present in usual designs. The hemisphere above the sample is mainly occupied by the electron column and leaves only a very small gap accessible for the NSMM to achieve a working distance of $20 \mathrm{~mm}$. The system presented here has been designed to be as compact as possible. The NSMM stage is mounted on the chamber vertically to the electron beam of the SEM.

The NSMM consists of two main components, a sample scanning stage and a probing unit [Fig. 4(a)]. The sample scanning stage is composed of an AFM scanner positioned onto a coarse positioning stage. The positioning stage consists of three piezo driven linear actuators manufactured by Smaract $\mathrm{GmbH}$ with scanning ranges of $26 \mathrm{~mm}$ in $\mathrm{X}$ and $\mathrm{Y}$ directions and $11 \mathrm{~mm}$ in $\mathrm{Z}$ direction. The actuators enable closed-loop operation with less than $10 \mathrm{~nm}$ resolution and $25 \mathrm{~nm}$ repeatability in any direction. The AFM scanner ANSxyz100/Std from Attocube ${ }^{\circledR}$ operates in open-loop on scanning ranges of $50 \times 50 \times 24 \mu \mathrm{m}^{3}$ with sub-nm positioning resolution and $0.1 \%$ scan repeatability. The RF probing unit consists of a millimeter-wave probe fixed on the sample stage associated to a laser detection system [Fig. 4(b)]. The RF probe consists of a modified 12Pt400B microwave probe from $\mathrm{RMN} \circledast$ to achieve $1-100 \mathrm{GHz}$ frequency operation. This probe consists initially of an ultra-sharp solid platinum probe tapered down to $10 \mathrm{~nm}$ and attached to a ceramic substrate. The design, fabrication and experimental results of the probe will be described in the extended version of the paper. 


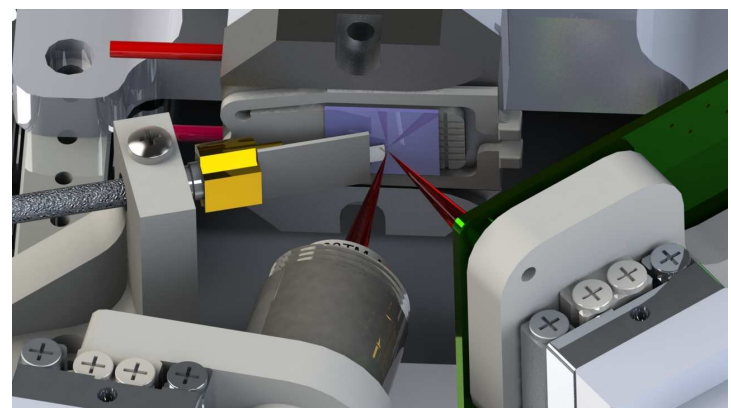

(a)

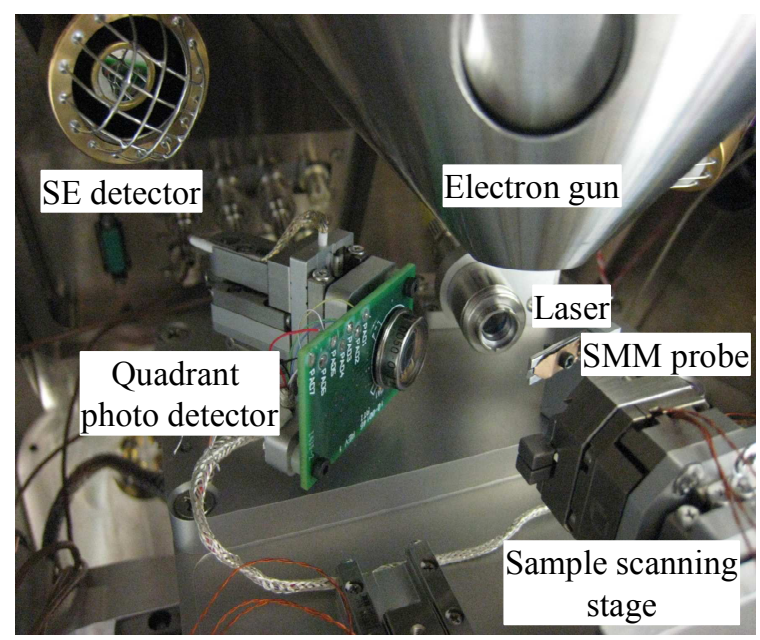

(b)

Fig. 4. (a) Sketch of the NSMM. (b) Photography of the NSMM inside a Tescan Mira XMU SEM.

First experimental results have been mainly focused on determining the performance in atomic force microscopy mode. To that end, silicon calibration grating from the $\mu \mathrm{MASCH}{ }^{\circledR}$ TGX01 and TGZ02 series have been imaged and used for AFM calibration. All measurements have been conducted using a conventional RMN probe mounted on a dedicated PCB [Fig. 5(a)]. Fig. 5(b) gives a topographic image performed on a TGZ02 sample. From the measured data, a RMS value of the roughness of $1.4 \mathrm{~nm}$ is extracted that is in good agreement with the sample specification (accuracy $=$ $1.5 \mathrm{~nm})$.

Microwave images using a verification kit developed by Keysight ${ }^{\circledR}$ and MC2-Technologies ${ }^{\circledR}$ that consists of sub-fF MOS capacitors are under investigation and will be provided in the final version of the paper.
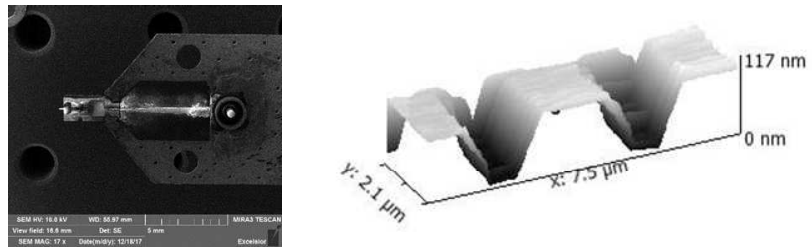

Fig. 5. (a) SEM image of the probe. (b) AFM image of a TGZ02.

\section{CONCLUSION}

FEM based EM simulations have been exemplary performed to highlight the main limitations encountered in NSMM applications. Although it has been widely accepted that the spatial resolution is mainly governed by the tip apex geometry, the wavelength of operation affects drastically the spatial resolution. Furthermore, water meniscus in the vicinity of the probe adds a parasitic capacitance especially when sub$100 \mathrm{~nm}$ nanodevices are considered. These results lead us to develop a new class of instrumentation that combines the advantages of atomic force microscopy, scanning electron microscopy and microwave/millimeter-wave measurements. The preliminary results obtained show that the proposed instrumentation is a promising solution to address the needs of characterization techniques with high spatial resolution.

\section{REFERENCES}

[1] S. M. Anlage, V. V. Talanov, and A. R. Schwartz, "Principles of nearfield microwave microscopy," Scanning Probe Microscopy: Electrical and Electromechanical Phenomena at the Nanoscale, S. Kalinin and A. Gruverman, Eds. New York, Springer Sci., pp. 215-253, Aug. 2007.

[2] S. Fabiani, D. Mencarelli, A. Di Donato, T. Monti, G. Venanzoni, A Morini, T. Rozzi, and M. Farina, "Broadband Scanning Microwave Microscopy investigation of graphene", Proc. IEEE MTT-S International Microw. Symp., pp. 1-4, June 2011.

[3] M. Farina, D. Mencarelli, A. Morini, L. Pierantoni, X. Jin and J. Hwang, "Developments of microwave microscopy for application to biological samples," 2017 International Conference on Manipulation, Automation and Robotics at Small Scales (MARSS), Montreal, QC, 2017, pp. 1-5.

[4] G. Gramse, M. Kasper, L. Fumagalli, G. Gomila, P. Hinterdorfer and F. Kienberger, "Calibrated complex impedance and permitivity measurements with SMM," Nanotechnology, vol. 25, no. 14, p. 8, 2014.

[5] A. Imtiaz, T. M. Wallis and P. Kabos, "Near-Field Scanning Microwave Microscopy: An Emerging Research Tool for Nanoscale Metrology”, IEEE Microwave Magazine, vol.15, no.1, pp.52-64, Jan. 2014.

[6] A. Imtiaz, T. M. Wallis and P. Kabos, "Near-Field Scanning Microwave Microscopy: An Emerging Research Tool for Nanoscale Metrology", IEEE Microwave Magazine, vol.15, no.1, pp.52-64, Jan. 2014.

[7] L. Zhang, Y. Ju, A. Hosol and A. Fujimoto, "Microwave atomic force microscopy imaging for nanometer-scale electrical property characterization," Review of Scientific Instruments, vol. 81, no. 12, pp. $123708,2010$.

[8] Agilent Technologies, Inc., "Scanning Microwave Microscopy (SMM) Mode", Datasheet, 2013.

[9] Oxford Instruments, Inc., "Scanning Microwave Impedance Microscopy (sMIM)", Datasheet, 2014.

[10] B. L. Weeks, M. W. Vaughn and J. J. Deyoreo, "Direct imaging of meniscus formation in atomic force microscopy using environmental scanning electron microscopy," Langmuir, vol. 21, no. 18, pp. 80968098, 2005.

[11] M. Calleja, M. Tello and R. Garcia, "Size determination of field-induced water menisci in noncontact atomic force microscopy," Journal of applied physics, vol. 92, no. 9, pr. 5539-5542, 2002.

[12] T. Dargent, K. Haddadi, T. Lasri, N. Clément, D. Ducatteau, B. Legrand, H. Tanbakuchi, and D. Théron, "An interferometric scanning microwave microscope and calibration method for sub-fF microwave measurements", Rev. Sci. Instrum., vol. 84, no.12, pp. 123705-1237057, Dec. 2013.

[13] F. Wang, N. Clément, D. Ducatteau, D. Troadec, H. Tanbakuchi, B. Legrand, G. Dambrine and D. théron, "Quantitative impedance characterization of sub-10 $\mathrm{nm}$ scale capacitors and tunnel junctions with an interferometric scanning microwave microscope," Nanotechnology, vol. 25 , no. 40 , pp. 405703, 2014. 